\title{
Exercise first-pass radionuclide ventriculography in detection of coronary artery disease
}

\author{
DAVID STONE, „ DUNCAN DYMOND, A T ELLIOTT, K E BRITTON, \\ S O BANIM, R A J SPURRELL
}

From the Departments of Cardiology and Nuclear Medicine, St Bartholomew's Hospital, West Smithfield, London

SUMMARY Thirty-four patients with coronary artery disease were exercised on a bicycle ergometer until they developed angina. There was a highly significant fall in ejection fraction from a mean of $61 \cdot 1$ to 52.9 which was more pronounced in the group with three vessel coronary artery disease. A coronary index was computed which took into account the extent and distribution of coronary artery lesions. Those patients with an index $<0.3$ (that is more severe disease) had greater falls in ejection fraction than those with higher indices. All five patients in whom there was a fall in ejection fraction of 15 per cent or more had triple vessel disease. Wall motion abnormalities were assessed by a hemiaxial method. Of 34 exercise-induced zones of wall motion abnormalities, 32 were in regions supplied by significantly stenosed coronary arteries.

A test was defined as positive if there was an abnormal exercise ejection fraction $(<50 \%)$, an exercise-induced wall motion abnormality, or a fall in ejection fraction at angina of at least 10 per cent. Of the 19 patients with triple vessel disease, $18(95 \%)$ had a positive result, as did 11 of $15(73 \%)$ patients with one or two vessel disease. A group of eight patients with normal coronary arteries were also exercised and in none of these was there a positive result. Exercise first-pass radionuclide ventriculography demonstrates changes in global and regional ventricular function in patients with coronary artery disease which are not present in normal subjects. It may also help to identify patients at high risk.

Since the main symptoms of ischaemic heart disease are present only at exercise, in recent years greater emphasis has been placed on the performance of the heart during stress. In the cardiac catheterisation laboratory both atrial pacing ${ }^{12}$ and hand grip exercise ${ }^{3}$ have been used to induce ischaemia. Sharma and Taylor ${ }^{4}$ reported a fall in ejection fraction on dynamic exercise in patients with coronary artery disease undergoing cardiac catheterisation.

Radionuclide ventriculography is a non-invasive procedure which allows exercise to be performed under more physiological conditions. Borer et al.,5 using equilibrium gated blood pool scanning in a modified left anterior oblique projection, demonstrated a fall in ejection fraction in patients exercised to angina. Bodenheimer et al., ${ }^{6}$ using the first-pass technique, also reported changes in regional ejection fraction in patients with ischaemic heart disease

* Supported by a grant from Bayer UK.

Received for publication 14 December 1979 during hand grip exercise.

First-pass radionuclide ventriculography has been validated against contrast angiograms in the detection of regional and general wall motion abnormalities at rest $^{7}$ and induced by pacing to angina. ${ }^{8}$

This study reports the changes in regional wall motion and ejection fraction induced by dynamic exercise to angina. It relates these changes to the extent and distribution of coronary artery lesions.

\section{Patients and methods}

Thirty-four patients were studied. There were 33 men and one woman whose ages ranged from 33 to 67 years (mean 51). All patients were being investigated for angina and underwent cardiac catheterisation. Beta-blocking drugs were stopped 48 hours before the investigation. Informed consent was obtained in every case. Eight control patients with normal coronary arteries were also investigated. 


\section{EXERCISE STUDIES}

The patients were positioned under the detector of the multicrystal gamma camera (Baird Atomic, System 77) in the $20^{\circ}$ right anterior oblique projection and the electrocardiogram leads attached (standard lead I). An intravenous cannula was inserted into an antecubital vein, preferably in the right arm. The feet of the patient were placed on the bicycle pedals and correct positioning ascertained by injecting a $1 \mathrm{mCi}$ bo! us of technetium- $99^{\mathrm{m}}$, as pertechnetate, with a saline flush. Electrocardiographic monitoring was carried out throughout the procedure.

The patients were then exercised on the bicycle ergometer in the supine position. The workload was increased by 25 watt increments every two minutes until the patient began to complain of angina. When the pain has reached moderate severity, the patient was asked to stop pedalling. A $10 \mathrm{mCi}$ bolus of technetium- $99^{\mathrm{m}}$ was injected with a rapid saline flush and counting was carried out for 50 seconds at a framing rate of 20 per second. Data were collected on to disc and stored on magnetic tape, correction having been made for dead-time of the instrument and for flood field nonuniformity.

Twenty minutes later a static background frame of residual blood pcol activity was counted with the patient in the same position as previously. Immediately afterwards the resting study was performed with a $15 \mathrm{mCi}$ bolus. This was corrected for residual blood pool background activity as well as for dead-time and non-uniformity before storage on magnetic tape.

\section{CORONARY ANGIOGRAPHY}

Coronary angiograms were performed by either the Sones or Judkins technique and coronary lesions were assessed by an independent observer.

\section{DATA ANALYSIS}

\section{Radionuclide angiography}

After transferring the data from tape to disc, serial frames of each study were summated over 1.5 second intervals and the left ventricular phase identified. A region of interest was selected over the left ventricle with a magnetic pen and grid array representing the 294 crystals of the detector. A time activity curve was generated and a background frame was selected from the pulmonary phase. Spatial and temporal correction were then automatically made during all further data processing for the exponential decay of lung activity. The peaks and troughs of the left ventricular phase, which represent end-diastole and end-systole, respectively, of each cardiac cycle, were used to derive ejection fraction and a representative cardiac cycle as previously described. ${ }^{9}$ End-systolic and end-diastolic images were obtained from this representative cycle and used to generate ventricular perimeters. This was achieved by an edge enhancement technique whereby the band of counts from 25 to 30 per cent of the maximum count ( $\mathrm{N} \max$ ) in any one cell was isolated and normalised to the image with the lower $\mathrm{N}$ max. The end-diastolic perimeters were then superimposed so that regional wall motion could be assessed.

Wall motion abnormalities were quantified by a hemiaxial method as used by Stone et al. ${ }^{8}$ This method was based on that described by Dwyer ${ }^{10}$ and Leighton et al. ${ }^{11}$ The long axis of the ventricle was drawn from the mid-point of the aortic valve plane to the apex. It was then trisected, and perpendiculars drawn from the points one-third and two-thirds of the distance along it to the ventricular perimeters at end-systole and enddiastole. Five hemiaxes were generated: two anterior, one apical, and two inferior, and the percentage shortening of each hemiaxis was calculated. The normal range of shortening of each hemiaxis was derived from the radionuclide ventriculograms of 22 patients without heart disease who were studied at rest (Table 1).

Hypokinesis of any hemiaxis was defined as a percentage shortening of less than two standard deviations below the mean percentage shortening of that hemiaxis in the normals. Akinesis was defined as absence of shortening of a given hemiaxis.

Table 1 Normal ranges of shortening for hemiaxial model

\begin{tabular}{ll}
\hline Hemiaxis & $\begin{array}{l}\text { Percentage shortening } \\
(\text { mean } \pm 2 S D)\end{array}$ \\
\hline 1 & $21-85$ \\
2 & $51-100$ \\
3 & $47-100$ \\
5 & $45-100$ \\
\hline
\end{tabular}

\section{CORONARY ANGIOGRAMS}

Coronary lesions were graded visually from 0 to 4 , where grade $0=$ normal; grade $1=25$ per cent stenosis; grade $2=50$ per cent stenosis; grade $3=$ 75 per cent stenosis; and grade $4=$ occlusion.

The extent of coronary disease was classified by two methods:

(1) Conventional separation into single, double, or triple vessel disease, where any lesion of grade 2 or more (that is greater than $50 \%$ ) was regarded as a significant stenosis. 
(2) In order to make greater allowance for position and extent of lesions a coronary index was computed by the method of Balcon et al. ${ }^{12}$

For the calculation of the index, the coronary tree was divided into 13 anatomical sections (Fig. 1). Each section was weighted according to size of lesion within it by the formula:

$$
\mathrm{Wi}=1-\frac{\mathrm{Gi}}{4}
$$

Where $\mathrm{Wi}$ is the weighting of the lesion in the $i$ th section, $\mathrm{Gi}$ is the grading of the lesion in the $i$ th section.

Thus the weighting is zero for an occluded segment and 1 for a patent one. An index was then calculated for each coronary artery separately:

$$
\begin{aligned}
& \text { LCI (left coronary index) } \\
& =\frac{W_{1}\left[W_{2} \times W_{3}\left(W_{4}+W_{5}\right)+W_{6}\left(W_{7}+W_{8}+W_{9}\right)\right]}{5}
\end{aligned}
$$

RCI (right coronary index)

$$
=\frac{\mathrm{W}_{10}\left(\mathrm{~W}_{11}+\mathrm{W}_{12}+\mathrm{W}_{13}\right)}{3}
$$

TCI (total coronary index)

$$
=\frac{5 \times \mathrm{LCI}+3 \times \mathrm{RCI}}{8}
$$

Thus allowance is made for the contribution of each vessel to total myocardial supply. In addition, because of multiplication of serial lesions, proximal stenoses will have proportionately greater effect.

The divisors in the formulae for the calculation of the individual indices are the number of terminal

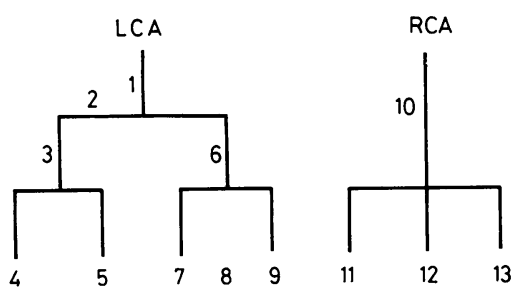

Fig. 1 Model of coronary tree for computation of index (1, left main stem; 2, 3, 4, divisions of left anterior descending; 5 , diagonal; 6 , main circumflex; $7,8,9$, lateral circumflex branches; 10 , right coronary artery; $11,12,13$, inferior left ventricular branches from right coronary artery).

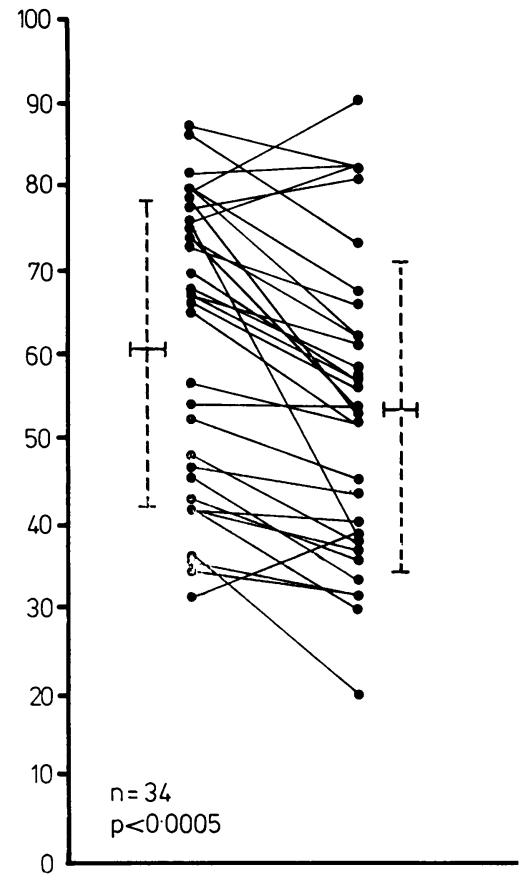

Fig. 2 Exercise-induced change in ejection fraction.

vessels. A normal system scores 1 , and the index progressively declines towards 0 as obstruction increases. If certain vessels are not present, the individual indices and final calculation are adjusted accordingly.

\section{Results}

\section{CORONARY LESIONS}

There were 19 patients with triple vessel disease, two of whom also had a significant left main stem stenosis, 10 with double vessel disease, and five with single vessel disease. Coronary index ranged from 0.075 to 0.875 . Seventeen patients had an index less than $0 \cdot 3$, and 17 an index higher than $0 \cdot 3$.

\section{GLOBAL LEFT VENTRICULAR FUNCTION}

The change in ejection fraction on exercise in all 34: patients with coronary artery disease is shown in Fig. 2. Mean ejection fraction fell from 61.1 per cent at rest to 52.9 per cent on exercise. This change was highly significant $(p<0.0005)$. In 27 patients ejection fraction fell, in four it rose, and in three it remained unchanged. In the eight normal patients who were also exercised, mean ejection fraction rose from $72 \cdot 1$ to 73.5 per cent. The patients with triple vessel disease had a highly significant fall in ejection fraction on exercise from a mean of 59.3 to 
47.9 per cent $(p<0.005)$. Though the group with single and double vessel disease also had a significant fall in ejection fraction from a mean of 63.3 to 59.4 per cent $(p<0.05)$, this was significantly less than for the group with triple vessel disease $(p<0.01)$ (Fig. 3). In 16 of the 19 patients with triple vessel disease ejection fraction fell on exercise and in three it remained unchanged. All five patients with a fall in ejection fraction of greater than 15 per cent had triple vessel disease. This subgroup contains the two patients with a significant left main stem stenosis.

Patients with an index less than 0.3 (that is the more extensive disease) had a highly significant fall in ejection fraction from 61.7 to 49.4 per cent $(p<0.0005)$. Again, this fall was significantly greater $(p<0.005)$ than that which occurred in the group with indices of over 0.3 (Fig. 4). All 17 patients with a coronary index of less than 0.3 had a fall in ejection fraction on exercise to angina.

\section{WALL MOTION CHANGES}

Thirty-four areas of wall motion abnormality were induced by exercise. Of these, 10 were anterior, 13 apical, and 11 inferior in location. All 10 patients who developed anterior wall motion changes had significant lesions in the anterior descending coronary artery. Of the 13 patients who developed apical wall motion abnormalities, 12 had lesions in either the anterior descending or circumflex systems. Of the 11 patients who developed inferior zones of

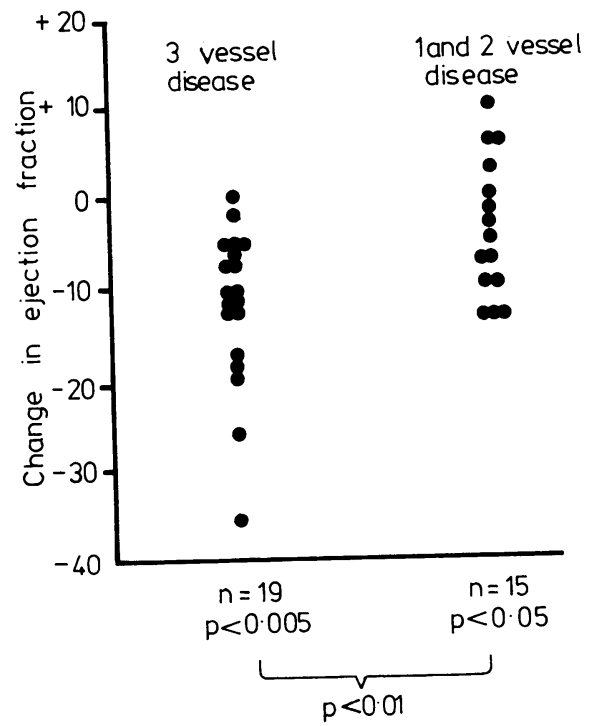

Fig. 3 Exercise-induced change in ejection fraction for single, double, and triple vessel disease.

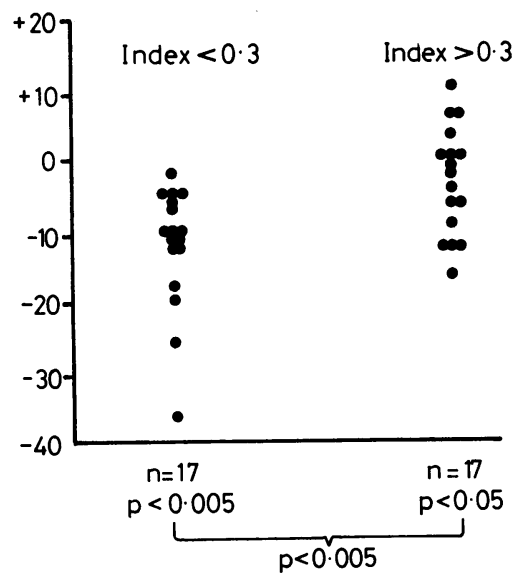

Fig. 4 Exercise-induced change in ejection fraction: coronary index.

wall motion abnormalities on exercise to angina, 10 had a lesion in either the right coronary artery or the atrioventricular branch of a dominant left circumflex system. Thus, of the 34 areas of exerciseinduced wall motion abnormalities, 32 were in regions supplied by significantly stenosed coronary arteries (Table 2).

Table 2 Exercise-induced areas of wall motion abnormality

\begin{tabular}{lll}
\hline & Number & $\begin{array}{l}\text { Subtended by } \\
\text { coronary lesion }\end{array}$ \\
\hline Anterior & 10 & 10 \\
Apical & 13 & 12 \\
Inferior & 11 & 10 \\
Total & 34 & 32 \\
\hline
\end{tabular}

\section{COMBINED ANALYSIS}

The combination of ejection fraction and regional wall motion data allows improved identification of patients with coronary artery disease (Table 3 ). We have defined a positive result as an exercise-induced wall motion abnormality, an abnormal exercise left

Table 3 Combined analysis in detection of coronary disease

\begin{tabular}{llll}
\hline & $\begin{array}{l}\text { No induced WMA, } \\
\text { normal exercise LVEF, } \\
\text { change in LVEF } \\
<10 \text { per cent fall }\end{array}$ & $\begin{array}{l}\text { Induced WMA or } \\
\text { abnormal exercise } \\
\text { LVEF or fall in } \\
\text { LVEF } \geqslant 10 \text { per } \\
\text { cent }\end{array}$ \\
\hline $\begin{array}{l}\text { Normal (8) } \\
\begin{array}{l}\text { Single and double } \\
\text { vessel disease (15) }\end{array}\end{array}$ & $8 \quad(100 \%)$ & 0 & $(0 \%)$ \\
$\begin{array}{l}\text { Triple vessel disease } \\
(19)\end{array}$ & $1(27 \%)$ & $11 \quad(73 \%)$ \\
\hline
\end{tabular}

WMA, wall motion abnormalities; LVEF, left ventricular ejection fraction. 


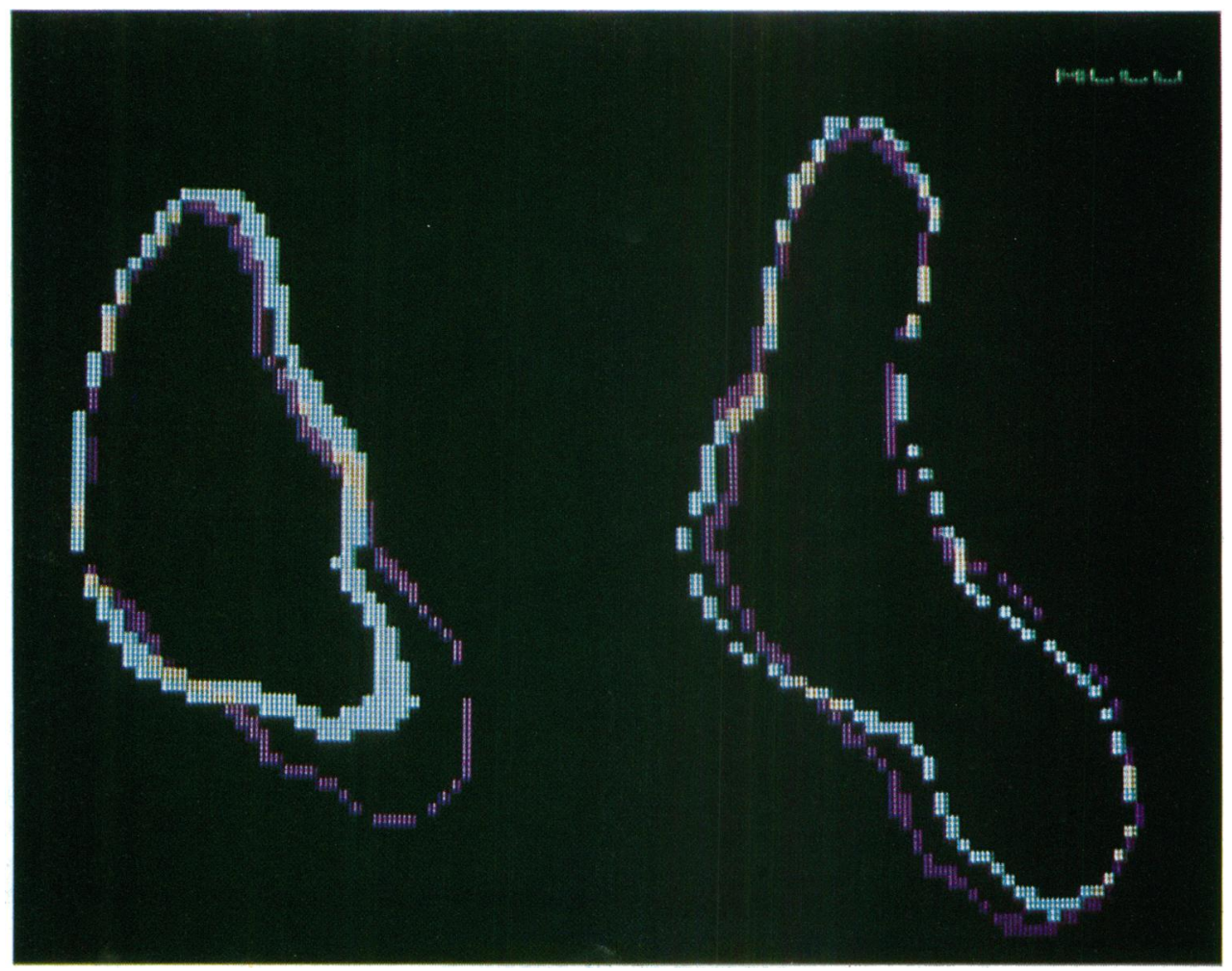

Fig. 5 Exercise-induced change in ventricular function in a patient with triple vessel disease. End-diastolic perimeter: mauve; end-systolic perimeter: turquoise.

ventricular ejection fraction $(<50 \%)$, or a fall in ejection fraction of at least 10 per cent on exercise. No normal patient had a positive result. Of 15 patients with single and double vessel disease, 11 had a positive result $(73 \%)$. Of the 19 patients with triple vessel disease, $18(95 \%)$ had a positive result and only one a negative test. Of the 17 patients with an index of less than $0.3,16$ had a positive result as did 12 of the 17 whose index was greater than 0.3 .

Fig. 5 shows the change in ventricular function induced by exercise to angina, in a patient with triple vessel disease. The end-diastolic perimeters are mauve in colour and the end-systolic perimeters turquoise. On the left is the resting study which shows symmetrical inward wall motion from the end-diastolic to the end-systolic perimeter. The study performed during exercise is shown on the right. There is extensive wall motion abnormality with apical akinesis and anterior and inferior hypokinesis. Ejection fraction fell from 75 per cent at rest to 39 per cent on exercise.

\section{Discussion}

It is accepted that impairment of left ventricular function occurs with the onset of ischaemia, ${ }^{13} 14$ but the investigation of ventricular function in patients with coronary artery disease has been mainly directed towards catheter laboratory studies at rest. ${ }^{15}{ }^{16}$ Sharma and Taylor ${ }^{4}$ showed a fall in ejection fraction on exercise during cardiac catheterisation, but did not investigate wall motion changes or relate their findings to extent of coronary disease.

By its very nature, exercise during cardiac catheterisation is an invasive and difficult procedure. The application of non-invasive radionuclide techniques to cardiology has allowed the assessment of cardiac function to be made during dynamic exercise tests which represent a more physiological state. Myocardial perfusion scintigraphy with thallium-201 is widely used, ${ }^{17} 18$ but there have been recent reports of its limitations. ${ }^{19-22}$ Though Borer et $a l .{ }^{5}$ report falls in ejection fraction in 
patients exercised to angina and investigated by equilibrium gated technique, in their study there was no quantitative assessment of wall motion abnormalities and no attempt was made to relate the changes seen to extent of coronary artery disease.

First-pass ventriculography offers certain advantages over the gated technique. Firstly, the rapid data acquisition time allows the assessment of contraction to take place over a very short period and therefore represents the function of the left ventricle at true exercise end-point. Secondly, since the right and left ventricles do not contain counts simultaneously, the right anterior oblique projection may be used. This is superior to the left anterior oblique in the assessment of regional wall motion in ischaemic heart disease. ${ }^{23-25}$ The firstpass technique has also been able to demonstrate wall motion changes at rest ${ }^{7}$ and pacing to angina ${ }^{8}$ which correlate with contrast angiography.

In this study we have shown that falls in ejection fraction may be shown by first-pass technique in patients with coronary artery disease. These falls were significantly greater for the group of patients with more extensive lesions. The five patients whose ejection fraction fell by more than 15 per cent all had triple vessel disease (including two with significant left main stem stenosis).

The use of coronary index to score lesions allows for the greater influence of proximal lesions on myocardial blood supply and also provides an overall assessment of the extent of coronary artery obstructions. Previous investigations have shown no relation between resting left ventricular function and a coronary score. ${ }^{16}$ The index used in the present study was described by Balcon et al. ${ }^{12}$ and has been correlated with prognosis and exercise tolerence in patients with coronary disease. In this study the degree of change of ejection fraction seen at angina was higher for those patients with a lower coronary index, indicating that stress ventriculography unmasks the effect of coronary lesions on myocardial performance.

A possible criticism of the methods is that two consecutive studies were analysed and that a consistent error might be introduced by always performing the exercise study before the resting one. However, Marshall et al. ${ }^{25}$ and Bodenheimer et al. ${ }^{7}$ have shown good agreement between successive first-pass investigations and that the order in which the respective obliques were used in a biplane study did not affect the results. Also the present study shows good separation between the groups of patients, all of whom were studied in the same way.

Wall motion abnormalities were analysed by a hemiaxial method based on that of Leighton et al. ${ }^{11}$ Bodenheimer et $a .^{7}$ used a similar method for resting nuclear angiograms and found a good correlation with contrast angiography. We have also reported previously a good correlation between nuclear and contrast angiography for pacinginduced wall motion abnormalities assessed by this hemiaxial model. ${ }^{8}$

There was an excellent association in this study between the region of wall motion abnormality and the site of coronary artery stenosis. Of 34 abnormal segments of contraction induced by exercise, 32 were in regions supplied by significantly stenosed coronary arteries. The regional information supplied by the technique depends on the use of the multicrystal gamma camera and should prove valuable, perhaps in combination with perfusion studies, in the assessment of the effects of interventions such as saphenous vein bypass surgery.

The combination of regional wall motion and ejection fraction data improved identification of patients with coronary disease. Eighteen of 19 patients with triple vessel disease had a positive exercise study and the overall success rate in the identification of patients with coronary artery disease was 29 of $34(87.5 \%)$. Thus the ability of this technique to demonstrate regional wall motion changes in the right anterior oblique projection is vital if the method is used in the screening of patients with coronary disease. The results are especially important in view of recent doubts about the ability of myocardial perfusion scintigraphy with thallium-201 to identify patients with triple vessel disease. ${ }^{20-22}$

Exercise first-pass radionuclide ventriculography is a non-invasive technique which provides regional and global assessment of ventricular function during angina. It should prove valuable in the screening and study of patients with ischaemic heart disease and may identify patients at high risk.

\section{References}

1 O'Brien KP, Higgs LM, Glancy DL, Epstein SE. Hemodynamic accompaniments of angina. Circulation 1969; 39: 735-43.

2 Rickards A, Seabra-Gomes R, Thurston P. The assessment of regional abnormalities of the left ventricle by angiography. Eur $\mathcal{F}$ Cardiol 1977; 5: $167-82$.

3 Krayenbuehl HP, Schoenbeck M, Rutishauser W, Wirz P. Abnormal segmental contraction velocity in coronary artery disease produced by isometric exercise and atrial pacing. Am $\mathcal{f}$ Cardiol 1975; 35: 785-94.

4 Sharma B, Taylor SH. Localisation of left ventricular ischaemia in angina pectoris by cineangiography during exercise. Br Heart $\mathcal{F}$ 1975; 37: 963-70. 
5 Borer JS, Bacharach SL, Green MV, Kent KM, Epstein SE, Johnston GS. Real-time radionuclide cineangiography in the noninvasive evaluation of global and regional left ventricular function at rest and during exercise in patients with coronary-artery disease. $N$ Engl f Med 1977; 296: 839-44.

6 Bodenheimer MM, Banka VS, Fooshee CM, Gillespie JA, Helfant RH. Detection of coronary heart disease using radionuclide determined regional ejection fraction at rest and during handgrip exercise; correlation with coronary arteriography. Circulation 1978; 58: 640-8.

7 Bodenheimer MM, Banka VS, Fooshee CM, Hermann GA, Helfant RH. Quantitative radionuclide angiography in the right anterior oblique view: comparison with contrast ventriculography. Am F Cardiol 1978; 41: 718-25.

8 Stone D, Dymond D, Elliott AT, Britton KE, Spurrell RAJ, Banim SO. Use of first-pass radionuclide ventriculography in assessment of wall motion abnormalities induced by incremental atrial pacing in patients with coronary artery disease. $\mathrm{Br}$ Heart $f$ 1980; 43: 369-75.

9 Dymond DS, Jarritt PH, Britton KE, Spurrell RAJ. Detection of post-infarction left ventricular aneurysms by first-pass radionuclide ventriculography using a multicrystal gamma camera. $\mathrm{Br}$ Heart f 1979 ; 41 : 68-78.

10 Dwyer EM Jr. Left ventricular pressure-volume alterations and regional disorders of contraction during myocardial ischemia induced by atrial pacing. Circulation 1970; 42: 1111-22.

11 Leighton RF, Wilt SM, Lewis RP. Detection of hypokinesis by a quantitative assessment of left ventricular cineangiograms. Circulation 1974; 50: 121-7.

12 Balcon R, Cattell MR, Stone DL, Fuerlicht J. A computer generated index for the assessment of coronary angiography. Acta Med Scand 1978; 615, suppl: 25-30.

13 Tennant R, Wiggers CJ. Effect of coronary occlusion on myocardial contraction. Am f Physiol 1935; 112: 351-61.

14 Banka VS, Helfant RH. Temporal sequence of dynamic contractile characteristics in ischemic and non-ischemic myocardium after acute coronary ligation. Am f Cardiol 1974; 34: 158-63.

15 Bruschke AVG, Proudfit WL, Sones FM Jr. Progress study of 590 consecutive non-surgical cases of coronary disease followed 5-9 years. Circulation 1973; 47: 1154-63.

16 Björk L, Cullhed I, Hallén A. Cineangiographic studies of the left ventricle in patients with angina pectoris. Circulation 1967; 36: 868-77.

17 Hamilton GW, Trobaugh GB, Ritchie JL, Williams DL, Weaver WD, Gould KL. Myocardial imaging with intravenously injected Thallium-201 in patients with suspected coronary artery disease. $\mathrm{Am} \mathcal{F}$ Cardiol 1977; 39: 347-54.

18 Botvinick EH, Taradash MR, Shames DM, Parmley WW. Thallium-201 myocardial perfusion scintigraphy for the clinical clarification of normal, abnormal, and equivocal electrocardiographic stress tests. Am $\mathcal{F}$ Cardiol 1978; 41: 43-51.

19 Mueller TM, Marcus ML, Ehrhardt JC, Chaudhuri T, Abboud FM. Limitations of Thallium-201 myocardial perfusion scintigrams. Circulation 1976; 54: $640-6$.

20 McKillop JH, Murray RG, Turner JG, Bessent RG, Lorimer AR, Greig WR. Can the extent of coronary artery disease be predicted from Thallium-201 myocardial images? f Nucl Med 1979; 20; 715-9.

21 Pierson RN, Alam S, Kemp HG, Friedman MI. Radiocardiography in clinical cardiology. Semin Nucl Med 1977; 7: 85-100.

22 Corne RA, Gotsman MS, Atlan H. Radionuclide assessment of regional myocardial perfusion with thallium-201. Am Heart $\mathcal{F}$ 1979; 97 : 112-8.

23 Jengo JA, Oren V, Conant R, et al. Effects of maximal exercise stress on left ventricular function in patients with coronary artery disease using first pass radionuclide angiocardiography. A rapid, non-invasive technique for determining ejection fraction and segmental wall motion. Circulation 1979; 59: 60-65.

24 Cohn PF, Gorlin R, Adams DF, Chahine RA, Vokonas PS, Herman MV. Comparison of biplane and single plane left ventriculograms in patients with coronary artery disease. Am $\mathcal{F}$ Cardiol 1974; 33: 1-6.

25 Marshall RC, Berger HJ, Costin JC, et al. Assessment of cardiac performance with quantitative radionuclide angiocardiography. Circulation 1977; 56: 820-9.

Requests for reprints to Dr D Stone, Department of Cardiology, St Bartholomew's Hospital, West Smithfield, London EC1A 7BE. 